\section{Haarausfall und Akne in der Pubertät schützen vor Hodenkrebs}

Für Jungen, die während der Pubertät unter Haarausfall und starker Akne leiden, gibt es jetzt ein kleines Trostpflaster. Sie werden später eher nicht an einem Hodentumor erkranken - zumindest laut einer aktuellen US-amerikanischen Studie.

$\mathrm{D}$ ie Androgenspiegel während des Teenageralters und der Adoleszenz scheinen Einfluss auf das spätere Hodentumorrisiko zu haben. Daher untersuchten US-amerikanische Wissenschaftler in einer Fall-Kontroll-Studie, ob ein Zusammenhang zwischen hormonbedingten Phänomenen wie Akne und Haarausfall während der Pubertät und dem Risiko eines späteren testikulären Keimzelltumors besteht.

Dazu werteten sie die Daten von 187 Tumorpatienten und 148 Kontrollen mithilfe eines logistischen Regressionsmodelles aus. Sie legten vor allem Augenmerk auf die Parameter Haarausfall, schwere Akne, Pubertätsbeginn und Körpergröße. Und tatsächlich: Je größer die kahlen Stellen am Kopf waren, je später der Haarausfall in der Pubertät einsetzte und je ausgeprägter er war, desto unwahrscheinlicher war eine Hodentumorerkrankung. Auch wenn die Probanden über eine ausgeprägte Akne in der Pubertät berichteten, war ihr Erkrankungsrisiko deutlich niedriger. Anders bei der Körpergröße: Wer groß gewachsen war, lief eher Gefahr an einem testikulären Keimzellkrebs zu erkranken $(p=0,02)$. All diese Parameter beeinflussten unabhängig von den bereits bekannten Risikofaktoren, wie Alter, Ethnie, früherer Kryptorchismus, aber auch sozioökonomischer Status, die Erkrankungswahrscheinlichkeit.

Fazit: Ein hoher endogener Androgenspiegel während der Pubertät senkt das Risiko eines späteren testikulären Keimzelltumors, schlussfolgern die Autoren und verweisen auf frühere Studien, die $\mathrm{zu}$ ähnlichen Ergebnissen kamen. Vor

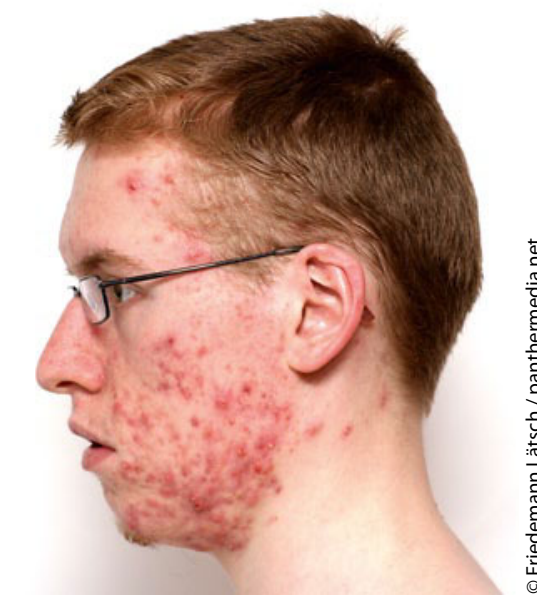

Er wird später voraussichtlich nicht an Hodenkrebs erkranken.

allem Dihydrotestosteron scheint direkt in die testikuläre Entwicklung einzugreifen. Die Autoren fordern nun weitere Studien, die unter anderem die Rolle der Androgensynthese und des Androgenmetabolismus bei der Tumorgenese zu klären versuchen.

Dr. Dagmar Kraus

Trabert B et al. Baldness, acne and testicular germ cell tumours. Int J Androl 2011;34: e59-67

\title{
Mit Vitamin E schneller zum Prostatakarzinom
}

Die SELECT-Studie, bei der die präventive Wirkung von Vitamin E und Selen auf die Krebsentstehung untersucht wurde, war 2008 wegen mangelndem Erfolg gestoppt worden. Die Nachbeobachtung der Probanden brachte nun weitere Ernüchterung.

n der SELECT-Studie (Selenium and Vitamin E Cancer Prevention Trial) waren im Jahr 2001 über 35.000 Männer in in vier Gruppen eingeteilt worden, um zu zeigen, dass Selen und Vitamin E einen Beitrag zur Krebsprävention leisten können. Die Probanden erhielten Selen $200 \mu \mathrm{g} / \mathrm{d}$, Vitamin E $400 \mathrm{IU} / \mathrm{d}$, eine Kombination aus beidem oder ein Placebo. Die Studie wurde im Jahr 2008 vorzeitig gestoppt. Grund hierfür war die Zwischenauswertung der Daten, die nicht den erhofften Schutz durch Vitamin E oder Selen erkennen ließ. Im Gegenteil, es hatte sich sogar eine Tendenz zu einem erhöhten Prostatakarzinomrisiko durch die Vitamin-E-Einnahme gezeigt. Darüber hinaus war im Selenarm die Zahl der Diabetes-Erkrankungen überdurchschnittlich angestiegen.

Um die möglichen Risiken von Selen und Vitamin E besser beurteilen zu können, wurden die Probanden auch nach Abbruch der Therapie weiterbeobachtet. Die letzte Datenanalyse vom 5. Juli 2011 umfasste nun zusätzliche 54.464 Personenjahre. In der Zeit von Oktober 2008 bis Juli 2011 traten 521 weitere Prostatakarzinome auf: 113 in der Placebogruppe, 147 in der Vitamin-E-Gruppe, 143 in der Selengruppe und 118 in der Gruppe, in der sowohl Vitamin E als auch Selen eingenommen worden waren. Damit war die Zahl in der Vitamin-E-Gruppe von 473 auf 620/8.737 gestiegen. Statistisch signi- fikant war die erhöhte Rate an Prostatakarzinomen insgesamt nur in der Gruppe Vitamin E allein versus Placebo. Erkennbar wurde diese Entwicklung nach dem dritten Studienjahr. Zu dieser Zeit lag das Risiko in der Vitamin-E-Gruppe um 10\% höher als in der Placebogruppe und stieg dann Jahr für Jahr langsam an. Zum Zeitpunkt der Diagnosestellung wurde in den meisten Fällen ein Gleason 6 festgestellt.

Fazit: Eine biologische Erklärung für die beobachtete Häufung von Prostatakarzinomen nach Vitamin-E-Supplementation ist anhand der Daten nicht möglich. Dass in der Kombinationsgruppe trotz VitaminE-Zufuhr keine signifikante Risikosteigerung zu erkennen ist, könnte den Autoren zufolge darauf hindeuten, dass Selen einen schützenden Effekt haben könnte und so das durch Vitamin E erhöhte Risiko wieder ausgleicht. Dr.Christine Starostzik

Klein EA et al. Vitamine $E$ and the Risk of Prostate Cancer. JAMA 2011; 306: 1549-56 